\title{
La danza contemporánea en España (1989-2009): aproximación a la creación coreográfica a través de la revista «Por la danza» Contemporary Dancein Spain (1989-2009): an aproach to the choregraphy performance through «Porla danza» magazine
}

\author{
Ma Paz Brozas Polo, Teresa García San Emeterio, Sara López Azcuna
}

Universidad de León

Resumen: Este estudio pretende identificar los principales elementos relativos a la creación coreográfica en el contexto español así como su evolución entre 1989 y 2009, a partir de los datos de la revista «Por la danza». Dicha revista de danza se constituye como un testigo privilegiado del desarrollo de la danza contemporánea en España en estas dos últimas décadas. Se analiza el lugar de la revista «Por la danza» en relación con las demás publicaciones que abordan la danza de forma más o menos específica y se revisan los 79 ejemplares publicados por la revista desde el punto de vista de las referencias relativas a la danza contemporánea: compañías, espacios de creación y festivales u otros eventos. Este estudio, a pesar del sesgo local de la revista que privilegia el entorno de Madrid, nos permite identificar un amplio conjunto de compañías españolas de danza y clasificarlas en función del grado de reconocimiento o consolidación y también del periodo de visibilidad. Se puede vislumbrar, además, la progresiva diversificación de los espacios y localidades de representación con el acercamiento a las artes plásticas y el incremento de eventos específicos de danza contemporánea y de nuevas artes fronterizas donde se acomoda la danza.

Palabra clave: danza contemporánea, revista, creación, coreografía.

\begin{abstract}
The aim of this study is to identify the main elements related to the choreographic creation in Spain as well as its evolution between 1989 and 2009, according to the information from the magazine «Por la danza». This magazine has been a privileged witness of the development of the contemporary dance in Spain in the two last decades. The study analyses the magazine's position with regards to other dance-related publications and revises their 79 issues from a contemporary dance point of view: companies, spaces of creation and festivals or other events. Although the study refers to a Madrid local dance magazine, a variety of Spanish dance companies has been included, as well as a detailed classification according to their recognition or consolidation degree and visibility period. The study also reflects the progressive increase of the number of performance spaces and locations where audience might approach to the plastic arts and specific contemporary dance events or frontier arts.
\end{abstract}

Key words: contemporary dance, magazine, creation, choreography.

\section{Introducción}

La producción teórica, la escritura y la investigación en torno a la danza son escasas en el contexto español y esta escasez se acentúa aún más en el caso de la danza contemporánea. El apoyo institucional resulta muy limitado y la aproximación universitaria muy embrionaria desde cualquiera de los campos del saber afines o interesados. Quizás el estímulo de la reciente consideración universitaria de los estudios de danza -iveinte años ya desde la LOGSE?- permita que este panorama se vaya modificando y los estudios de posgrado materializando poco a poco en trabajos y tesis, aunque hasta ahora no se detecta apenas el reflejo en encuentros ni en publicaciones.

En octubre y noviembre de 2009 se elaboraron sendos planes para el desarrollo de la danza en los gobiernos catalán y español; en estos planes se incluye el desarrollo de la formación y la reflexión en torno a la danza; así en el Plan Integral para la Danza de Cataluña se incluye, entre las diversas medidas, la elaboración de un mapa de espacios de creación, y en el Plan General de la Danza (INAEM 2009) la creación del nuevo centro de recursos que pretende asumir el observatorio de la danza y la elaboración de una guía de recursos (Arantzibia, 2010). Si estos planes se llevan a cabo pueden contribuir en cierta medida al desarrollo de la investigación en materia de danza en nuestro contexto.

Por otra parte, desde las ciencias de la actividad física, perspectiva en la que nos situamos las autoras, apenas se ha estimado la danza como objeto de estudio, en ocasiones ni siquiera se ha reconocido como actividad física o corporal; un dato positivo ha sido la reciente creación del Grado en Ciencias de la Danza en la Facultad de Ciencias de la Actividad Física y del Deporte de la Universidad Europea de Madrid, pero de momento, los esfuerzos y resultados más fructíferos en

Fecha recepción: 26-10-10 - Fecha envío revisores: 04-01-11 - Fecha de aceptación: 0-05-11 Correspondencia: Ma Paz Brozas Polo

Facultad de Ciencias de la Actividad Física y del Deporte (FCAFD)

Campus de Vegazana S/N - 24071 León

E-mail: mpbrop@unileon.es investigación vienen, sobre todo, del ámbito de la historia y de la gestión de las artes escénicas.

En cuanto al panorama general de las publicaciones periódicas de danzà en España, no resulta fácil de analizar: la pervivencia de una revista a lo largo de las décadas, como sucede con las propias compañías y los espacios para la creación, es ya un gran mérito.

Actualmente, tras revisar una lista aproximada de cuarenta títulos de publicaciones periódicas dedicadas a la danza en España -muchos de ellos de publicación irregular o ya desaparecidos-, en el perfil de Por la danza podemos incluir unas pocas revistas, de ámbito nacional y de temática y orientación similares: las publicaciones impresas Ddanza (antes ConDdeDanza, aparecida en Valenciaen 2003) y SusyQ (Madrid, 2005), y la revista digital $E-d n z$ (Madrid, 2010), mantienen el mismo carácter multidisciplinar y divulgativo, aunque son mucho más jóvenes que Por la danza.

Para hablar de revistas especializadas en danza contemporánea hay que trasladarse a Cataluña donde, tras algunas desapariciones importantes, toman el relevo las publicaciones del Mercat de les Flors, Reflexiones en torno a la danza (2006) y de la red CQD, Ciudades que danzan. Danza en paisajes urbanos (2007), publicadas íntegramente en formato digital, puntuales y hasta el momento regulares, que muestran el paisaje de una danza contemporánea reflexiva, siempre atenta a las intenciones de los procesos creativos. En esta misma línea podemos nombrar la revista DCO, Danza, cuerpo yobsesión, revista iberoamericana de coreografía y pensamiento del cuerpo aparecida en 2004.

Cairon. Estudios de danza (Universidad de Alcalá de Henares, 1995) es la revista pionera en España en afrontar la danza desde una perspectiva científica, así como El círculo de la danza (Universidad Rey Juan Carlos), Tiempo de danza (Universidad de Murcia, 2005), Diálogos de danza (CentroCoreográficode Valencia, 2004), y Danzaratte (Conservatorio de Málaga, 2006), aunque a veces irregulares o intermitentes en su publicación, representan también el esfuerzo de los centros de estudios superiores de danza por producir y difundir trabajos específicos. 
El Ministerio de Cultura intenta sistematizar los estrenos dancísticos que suceden en España en el anuario Pasos, y desde la iniciativa privada el asociacionismo se revela como un importante motor en la creación y difusión de revistas especializadas -Zaradanza, Danza en escena-.

Así, nuestro estudio, que responde a un deseo de investigación que abarca el desarrollo de la danza contemporánea en España en las tres últimas décadas, se ve nutrido, en la revisión de la documentación y edición sobre danza contemporánea, de los datos que aporta Por la danza, revista que no tiene carácter científico ni teórico sino, sobre todo, divulgativo, como le ocurre a la mayoría de las revistas de danza en España, pero que sí genera y sistematiza una gran base de datos específica sobre la danza que puede resultarnos valiosa para una aproximación histórica, dada su continuidad temporal -y excepcional regularidaddesde sus primeros números en 1989 hasta hoy. El inicio de la revista a finales de los ochenta constituye un evento más entre los que sucedieron en esos años de eclosión de la danza contemporánea en España, en los que se crearon compañías y se abrieron espacios aún hoy en desarrollo. Eclosión es el término que utiliza Giménez $(2001,9)$ para definir el periodo 1985-1989 en su estudio de la danza contemporánea en la comunidad valenciana y también es el término que usan Martínez y Menéndez (1999, 366-369) en el análisis del surgimiento de la danza contemporánea en España desde sus inicios a finales de los 70.

Basándonos en una metodología cualitativa utilizamos la aproximación bibliométrica, en cuanto a la sistematización y cuantificación de datos referentes a compañías, espacios y eventos, como referencia para la descripción, interpretación y análisis de la evolución de la danza en estos fecundos veinte años (1989-2009) que abarca el registro de los datos.

\section{Objetivos}

El objetivo de este estudio es el análisis de contenido de la revista Por la danza en cuanto a los aspectos específicos de la danza contemporánea desde la perspectiva de la creación. Para la selección y distinción de la acepción danza contemporánea respecto de otras tipologías hemos tenido en cuenta la terminología y calificación utilizada por la propia revista así como por los autores o protagonistas de cada actividad o evento citado.

Como punto de partida definimos un conjunto de interrogantes: nos preguntamos ¿qué elementos condicionan, determinan o permiten el desarrollo de la creación coreográfica en estos últimos años en nuestro heterogéneo contexto?, ¿qué apoyos?, ¿qué espacios escénicos o de residencia permiten los procesos y los productos de la danza? y ¿cuál es la visibilidad de dicha creación coreográfica en la revista Por la danza?

A priori estamos de acuerdo con Martínez y Menéndez (1999, 369) en que «la mayoría de las formaciones tienen vida intermitente, ya que se crean para un montaje determinado y luego se disuelven o recomponen dando lugar a grupos de nuevo nombre». Teniendo en cuenta esta fragilidad de las compañías de danza contemporánea, los nombres, las personas, así como las relaciones temporales entre coreógrafos y bailarines, nos cuestionamos si puede ser un criterio de calidad y buen hacer la pervivencia de una compañía. Aunque creemos que no siempre es así, sílo podemos considerar, sin embargo, un síntoma de existencia, de perseverancia y resistencia o quizás también de capacidad de visibilidad y representación.

Buscamos, por tanto, un análisis aproximativo de las compañías, los espacios y otros datos que acompañan, rodean y confluyen en la representación de una pieza de danza contemporánea tal como se recogen en esta revista objeto de estudio.

\section{Metodología}

A partir de una visita al Centro Nacional de Documentación del Instituto Nacional de las Artes Escénicas y de la Música en Madrid, se comienza el estudio previo sobre el estado de las publicaciones en Danza en España, que se completa con información on line, y se plantea el vaciado de la revista Por la danza.
La recogida de los datos se ha realizado en dos fases: en la primera, durante los primeros meses de 2010, se revisaron los 54 números disponibles en la Biblioteca Central de la Universidad de León (febreromarzo 1997 hasta otoño 2009); en la segunda fase, en julio de 2010, se revisaron los 25 primeros números y, por tratarse de números agotados, el proceso se realizó en la sede de la Asociación de Profesionales de la Danza en la Comunidad de Madrid, donde se encuentran dichos documentos. Agradecemos la colaboración de dicha Asociación y en particular de Anabel Poveda, coordinadora de la revista Por la Danza. En total se han utilizado datos de los 84 primeros números agrupados en 79 ejemplares, algunos de ellos dobles.

Además de la revisión de la documentación, se ha procedido a la estructuración del contenido a través de la definición de distintos campos introducidos en una hoja de cálculo del programa Excel 2003.

Los campos de estructuración de los datos son los siguientes:

1. Fecha: aunque en la recogida de datos inicial se registraron los números y fechas de las publicaciones, que tienen carácter trimestral, se optó por simplificar el seguimiento cronológico en años naturales.

2. Compañía: además del nombre de la compañía de danza se anotaron los nombres de los directores/coreógrafos, que en algunos casos coinciden o se incluyen en el de la propia compañía y en otros no; pensamos que este registro puede ayudar a determinar el grado de vinculación entre la compañía y los coreógrafos y/o bailarines implicados.

3. Espacios: de representación y/o presentación al público y también espacios de formación, en particular los que realizan la doble función de acoger el proceso y el producto coreográficos. Se elaboraron dos tablas diferenciadas de espacios de creación y de formación si bien los datos de la segunda se desecharon para este artículo por motivos de acotación.

4. Otros: en este apartado se anotaron los datos referidos a entidades de apoyo así como a festivales o eventos directamente relacionados con las puestas en escena.

El estudio conjunto de todos los datos y el análisis de resultados se realizaron en septiembre y octubre de 2010. En esta fase se consultaron además otras fuentes bibliográficas y documentales que permitieron el contraste y la comprensión de los datos de la revista.

Los resultados obtenidos de la revisión de Por la danza se han organizado en grupos y los datos de cada grupo se han estructurado en tablas: la primera relativa a las Compañías de danza contemporánea, la segunda se refiere a los Festivales y Eventos, y la tercera a los Espacios escénicos. En todos ellos, se utiliza en primer lugar el orden de aparición cronológica, y como segundo criterio el número de años de presencia en la revista; en caso de coincidencia se aplica finalmente la ordenación alfabética.

\section{Resultados}

\subsection{Compañías de Danza Contemporánea}

Entendemos que, en la mayoría de los casos, el año de aparición de una compañía de danza indica que existe un periodo previo de gestación, que podría abarcar incluso varios años de creación y quizás de proyección en medios de prensa más próximos a su centro de trabajo. Esta idea se puede constatar en casos comoel de Danat Dansa, que aparece registrada en 1991, cuando nos consta la existencia de la compañía desde 1984 (Van der Meer 1990, 76): faltarían pues referencias del año 1990 porque en el primer número, el de 1989 no aparecen crónicas de compañías, por lo que se ha excluido este año de la tabla. Otro ejemplo es el de la compañía Mudances, creada en 1985 (Margarit, 2000), y registrada sin embargo en 1998: faltarían 9 años de actividad sin registrar, del 90 al 98.

Desde un punto de vista cuantitativo, en función del reconocimiento o presencia de la compañía a lo largo de los años en la revista podemos distinguir en este estudio al menos tres grupos: compañías consolidadas, compañías estables y compañías breves. Los dos primeros grupos se incluyen en la Tabla 1.

En el primer grupo, como compañías reconocidas o consolidadas en el contexto de Por la danza hemos considerado a todas las compañías que se acercan a la decena de años activos en la revista incluyendo las que aparecen en más de ocho años. 


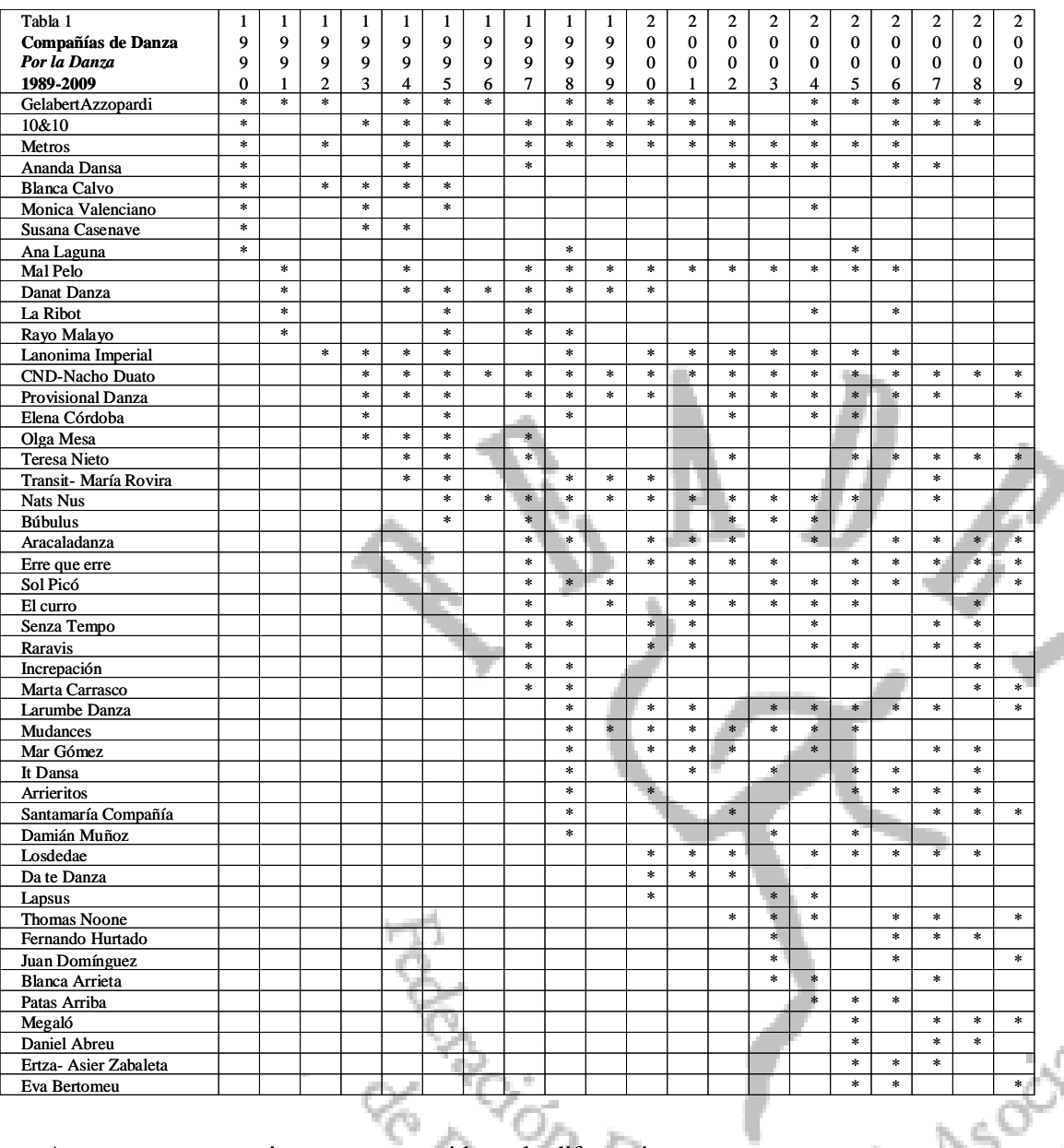

A este respecto, es importante considerar la diferencia entre compañías de autor y compañías de gran formato siendo el caso más extremo el de la Compañía Nacional de Danza de Nacho Duato, la cual aparece 17 años de forma ininterrumpida en la revista desde 1993 hasta elúltimo número registrado en el 2009, marcando el record de presencia con el máximo coeficiente de constancia y detrás de Gelabert Azzopardi en el tamaño del rango, ya que ésta aparece en todos los números, teniendo en cuenta que en el primero, 1989, no se registra la actividad de ninguna compañía y sólo está ausente en el 2009. En este grupo todas las compañías se crean en el siglo XX, las compañías visibles a partir del año 2000 aparecen en todo caso en el segundo grupo, como compañías estables. En éstas, la actividad registrada oscila entre tres y siete años. Algunos casos como el de Blanca Calvo son difíciles de registrar, debido a las diversas compañías en las que participó fruto de su colaboración con otras coreógrafas. En este caso con María Ribot fundó Bocanada Danza, una compañía activa en 1986-87 y 88 que reapareció en 1992 participando en unas Trayectorias de la Danza Madrileña presentando en el Teatro Pradillo una retrospectiva titulada Unos estupendos años. Véase al respecto ARTEA, el Archivo Virtual de Artes Escénicas de La Universidad de Castilla La Mancha y el artículo de Bravo (1990, 116117).

En este segundo grupo, si nos fijamos en compañías que ya tenían actividad en 1990, destaca la falta de continuidad en la visibilidad de compañías, que constituyen en gran medida compañías de autor y con un índice de constancia muy bajo, por ejemplo la compañía de Ana Laguna aparece en tres ocasiones a lo largo de 16 años. Cada caso responde a diferentes razones como pueden ser procesos migratorios (Laguna, 2009), falta de conexión, medios o interés por la proyección en la revista, etc. Artistas de reconocimiento internacional como La Ribot que figuran en este grupo pueden responder asimismo a una tendencia o evolución de su danza hacia la performance u hacia otras artes (Heathfield, 2004).

Por otra parte, en función del momento de aparición de la compañía podemos distinguir compañías pioneras, tardías y nuevas compañías.
Creemos que en España, y no en otros contextos, es posible considerar pioneras a las compañías que aparecieron antes de los 90. Tardías denominamos a las que se dan a conocer ya en la última década del siglo XX y nuevas compañías a las que se presentan ya en el siglo XXI.

Además, en la evolución cronológica se detectan momentos de mayor incorporación de compañías. Así, desde el punto de vista del nacimiento y/o proyección de las compañías se pueden distinguir varios momentos críticos:

-1990: corresponde a las compañías que nacieron en los 80 , la mayoría a mediados; se trata en todos los casos señalados de compañías con sede en Cataluña. De las ocho compañías registradas en este año la mitad permanecen visibles a lo largo de las dos décadas.

-1993/94: se incorpora un grupo numeroso de compañías, y ya no se trata solo de compañías catalanas, sino sobre todo ubicadas en esos años en Madrid como Provisional Danza y Teresa Nieto. Destaca además, entre ellas, la Compañía Nacional de Danza y también creadoras independientes como Elena Córdoba y Olga Mesa.

-1997/98: se produce un fuerte impulso de visibilidad a compañías de diversa índole y procedencia; destaca la alta presencia de Sol Picó como compañía de una sola bailarina, y el relativo nivel de registro de Märta Carrasco.

-2005: a partir de 1998 la incorporación de nuevas compañías al registro se realiza de forma mucho más progresiva hasta el 2005 donde detectamos el último impulso de incorporación de un conjunto de compañías. Además de las compañías recogidas en la Tabla 1 hemos registrado por orden cronológico las compañías de uno o dos años de presencia.

\subsection{Festivales y Eventos}

En el registro inicial en el Excel configuramos el campo de «Otros» junto a, «Compañías» $\mathrm{y}$ «Espacios» pensando en un conjunto de eventos o actividades que pueden acompañar el proceso de creación y representación. Observamos que la gran mayoría de estos eventos eran festivales. Junto a los festivales registramos además otras acepciones menos frecuentes como celebraciones, maratones, ciclos, jornadas, muestras y/o certámenes. Véase Tabla 2.

De la observación del abanico de eventos en los que se presentan las obras de danza contemporánea es preciso señalar que no se trata solamente de eventos específicos de danza contemporánea, ni siquiera específicos de danza. Así, por ejemplo, los encuentros pueden ser de artes escénicas, como es el caso del Festival de Otoño en Madrid o del GREC en Barcelona por citar dos de los más veteranos y constantes; en este último se encaja a su vez Dies de Danza como un acontecimiento específico para la danza contemporánea abierto a espacios públicos en varias localidades. Si la danza en su conjunto se sitúa dentro de las artes escénicas e incluso dentro del teatro, la danza contemporánea refuerza aún más su carácter interdisciplinar en el marco de Festivales como Escena Contemporánea o Trielemento en Madrid, en éste se reivindica la mezcla de técnicas de teatro, música y danza en un mestizaje trinitario que da nombre al festival. La danza se une no sólo al teatro sino a la música comoen el Festival Internacionalde Música y Danzade Granada. Por otro lado, la danza contemporánea aparece repetidas veces en eventos Contemporáneos o Alternativos pero también, en alguna ocasión en el 


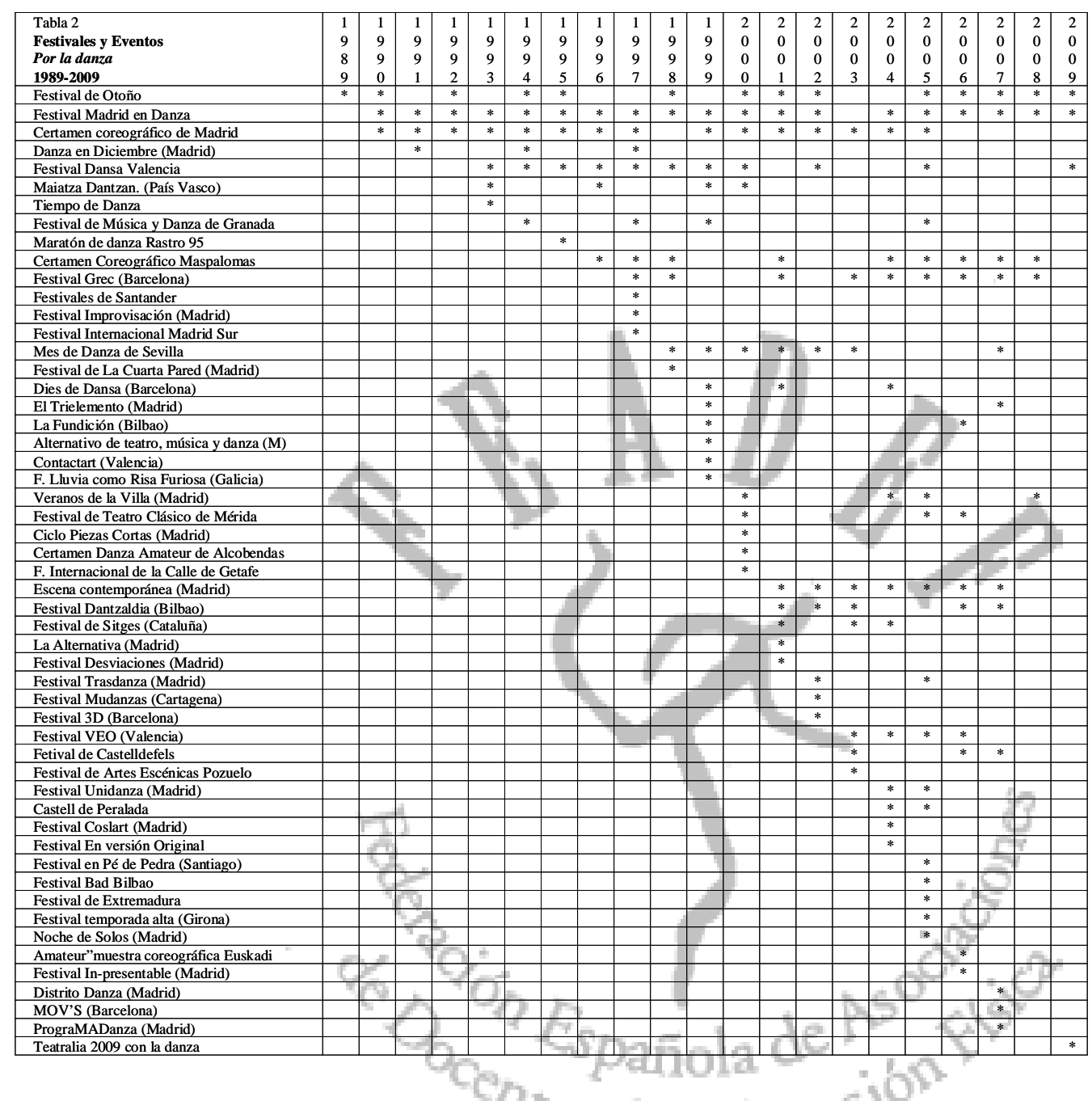

para la danza en este apartado. Así en la Tabla 3 sobre Espacios escénicos, donde se recogen los citados al menos en dos años, Madrid abarca quince espacios diferentes, cuatro Barcelona, tres Bilbao, dos Valencia y uno Santiago, Santander y Sevilla. La tendencia de la danza contemporánea a descentralizarse que apuntan autores como Esteller (2010) apenas se detecta en Por la danza.

En cualquier caso, se trata de espacios teatrales en su mayoría, pocos especializados en danza; no obstante, destacan por su especificidad algunos que presumen de ello como el Teatro de Madrid; asimismo, el ahora centro de arte contemporáneo $L a$ Fundición en Bilbao fue creado en 1986 como escuela de danza por la compañía Luque

seno de eventos de Teatro Clásico como en el caso del festival de Mérida. Por su parte, entre los festivales de danza sin más calificativos con un gran espacio para la danza contemporánea destacan Dansa Valencia y en los últimos años Unidanza (Madrid).

Por otro lado, se observa cómo la organización de estos festivales y eventos puede responder directamente a propuestas de espacios escénicos como el Teatro Pradillo o La Cuarta Pared en Madrid, La Fundición en Bilbao o el Mercat de les Flors en Barcelona. Además, la iniciativa privada también puede surgir directamente desde una compañía, como en el Certamen Coreográfico de Madrid que fue fundadoen 1987 por Paso a 2, y desde el 2000 se celebra en el Teatro Fernán Gómez Centro de Arte, en el registro aparece entre 1990 y 2005. Quizás una excepción de especial interés sea el Certamen Coreográfico de Maspalomas en las Palmas de Gran Canaria por su ubicación descentralizada, su definición como evento específico de danza contemporánea y la iniciativa de una persona apoyada por una institución municipal.

Sobre los marcos geográficos que sostienen estos eventos, denotando en general una actividad que les respalda, coinciden grandes centros urbanos como Madrid, Barcelona, Bilbao, Sevilla, Valencia o Las Palmas.

\subsection{Espacios y localidades}

Las referencias geográficas sobre los espacios también denotan, quizás en la misma medida, el carácter local de la revista y/o el carácter centralista de la danza contemporánea en España. Así por orden de visibilidad podemos señalar las siguientes comunidades y localidades: Madrid, Cataluña (Barcelona, Sitges, Castelldefels), País Vasco (Bilbao, San Sebastián), Valencia (Alicante, Castellón), Santander, Andalucía (Sevilla, Granada), Galicia (Santiago, Vigo), Canarias (Las Palmas). Sobre La Rioja (Logroño) y Extremadura (Mérida) aparecen referencias aisladas y en otras comunidades ni siquiera aparecen rastros de sus espacios
Tagua P.A. La Caldera en Barcelona aparece recogida muy tímidamente $(1999,2003)$ quizás por ser un espacio de representación pero sobre todo de creación y formación: se presenta como Centro de creación de danza y artes escénicas contemporáneas a partir del acuerdo de varias compañías en 1997 en Barcelona. Otro caso destacable por su inclinación hacia la danza es el del Mercat de les Flors, que nació en 1985 como teatro municipal, y desde el 2007 aspira a ser un centro de referencia para la investigación, producción, creación y difusión de la danza y las artes del movimiento.

Destaca como el espacio más nombrado La Cuarta Pared de Madrid desde 1995 hasta hoy, un espacio creado en 1985 por artistas de diversas procedencias teatrales pero con fundamentos ideológicoestéticos similiares. En el caso del Teatro Lliure, muy antiguo pero con progresivas modelaciones, las últimas de las cuales creemos que han permitido la incorporación de la danza y la danza de formato pequeño (Sala Petit) en su programación. También subrayamos la presencia de espacios teatrales como el Teatro Fernán Gómez de Madrid que con el subtítulo Centro de Arte se abren a otras manifestaciones artísticas permitiendo porosidades entre el teatro y las otras artes.

Hemos de señalar como caso significativo el de Sevilla donde tenemos registros de la ciudad de forma continua entre 1998 y 2005 pero sin referencia a espacios escénicos concretos, sólo al Teatro Central a partir del 2007, entendemos que gran parte de la actividad de esta ciudad se corresponde con el festival Mes de danza que hizo su edición XVII en el 2010 y se realiza en múltiples espacios públicos cerrados y abiertos, en la última edición tuvo como espacio prioritario el Centro de las Artes.

En el análisis de los datos relativos a los espacios se puede vislumbrar cierta tendencia hacia la diversificación en los últimos años. Así junto a los espacios escénicos propiamente dichos aparecen espacios de formación como el Instituto Francés de Madrid desde 1997, la Sala Fernando de Rojas del Círculo de Bellas Artes de Madrid (2000), o la 


\begin{tabular}{|c|c|c|c|c|c|c|c|c|c|c|c|c|c|c|c|c|c|c|c|c|}
\hline Tabla 3 & 1 & 1 & 1 & 1 & 1 & 1 & 1 & 1 & 1 & 1 & 2 & 2 & 2 & 2 & 2 & 2 & 2 & 2 & 2 & 2 \\
\hline Espacios escénicos & 9 & 9 & 9 & 9 & 9 & 9 & 9 & 9 & 9 & 9 & 0 & 0 & 0 & 0 & 0 & 0 & 0 & 0 & 0 & 0 \\
\hline Por la danza & 9 & 9 & 9 & 9 & 9 & 9 & 9 & 9 & 9 & 9 & 0 & 0 & 0 & 0 & 0 & 0 & 0 & 0 & 0 & 0 \\
\hline $1989-2010$ & 0 & 1 & 2 & 3 & 4 & 5 & 6 & 7 & 8 & 9 & 0 & 1 & 2 & 3 & 4 & 5 & 6 & 7 & 8 & 9 \\
\hline Sala Olimpia (Madrid) & & $*$ & $*$ & $*$ & $*$ & $*$ & & $*$ & & & & & & & & & & & & \\
\hline Teatro Álbeniz (Madrid) & $*$ & & & & & $*$ & & $*$ & $*$ & & & & & & & & & & & \\
\hline Centro Cultural de la Villa (M) & $*$ & & & & & & & & & & & $*$ & & & $*$ & & $*$ & $*$ & & \\
\hline Teatro Sala Pradillo (Madrid) & & & & * & & * & & $*$ & & & & & & & * & * & $*$ & $*$ & * & * \\
\hline Teatro de la Zarzuela (Madrid) & & & & & $*$ & & & & & & & & * & $*$ & & $*$ & & & $*$ & * \\
\hline Sala Cuarta Pared (Madrid) & & & & & & * & & $*$ & $*$ & * & * & * & & $*$ & $*$ & * & $*$ & $*$ & $*$ & * \\
\hline Mercat de les Flors (Barcelona) & & & & & & $*$ & & & $*$ & & & * & * & $*$ & & * & & $*$ & $*$ & * \\
\hline L'Espai, (Barcelona) & & & & & & * & & & $*$ & * & * & * & & * & * & * & & & & \\
\hline Palacio de Festivales de Santander & & & & & & * & & $*$ & $*$ & & & & & & & & $*$ & & & \\
\hline Teatro Principal (Valencia) & & & & & & & $*$ & & & & & & & $*$ & $*$ & $*$ & $*$ & & & * \\
\hline Instituto Francés (Madrid) & & & & & & & & $*$ & $*$ & & * & & * & & & & & & & \\
\hline Teatro Madrid & & & & & & & & $*$ & & * & & & & & & $*$ & & & & \\
\hline La Fundición (Bilbao) & & & & & & & & & & * & & & & $*$ & $*$ & & $*$ & & & \\
\hline Teatro o Sala Triángulo (Madrid) & & & & & & & & & & * & & & & 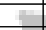 & 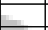 & & & $*$ & $*$ & * \\
\hline La Caldera (Barcelona) & & & & & & & & & & * & & & & * & & & & & & \\
\hline Círculo de Bellas Artes (Madrid) & & & & & & & & & & & * & & & & 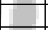 & $*$ & & & & \\
\hline Teatro Galán (Santiago) & & & & & & 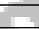 & & & & & * & & & & & $*$ & & & & \\
\hline Teatro Real de Madrid & & & & & & & 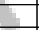 & & & & & $*$ & & * & * & $*$ & & + & $*$ & * \\
\hline Teatre Lliure (Barcelona) & & & & & & & 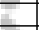 & & & & 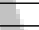 & * & & $*$ & $*$ & $*$ & & L & 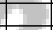 & \\
\hline Sala Mirador (Madrid) CNC & & & & & & 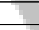 & Z & & & & 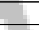 & * & & 4 & & & & $=$ & $*$ & \\
\hline Teatre Principal de Valencia & & & $+\frac{1}{4}$ & & & & at & 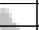 & & 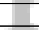 & 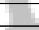 & & & $*$ & $*$ & & * & Ent & The & * \\
\hline Teatro Rialto (Valencia) & & & +4 & 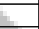 & & & 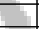 & +0 & & 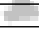 & 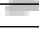 & & 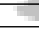 & $*$ & & $*$ & & 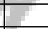 & & \\
\hline Sede del Curro DT (Madrid) & & 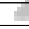 & th & 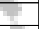 & & & 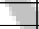 & 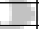 & & & & & & & $*$ & $*$ & - & $*$ & & \\
\hline Universidad Carlos III de Madrid & & & +4 & 4 & & & 2 & - & & & & & & & $*$ & $*$ & 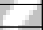 & & & \\
\hline Palacio Euskalduna (Bilbao) & & & & & & & & & & & & & & & $*$ & & & * & & \\
\hline Teatro de la Abadía (Madrid) & & & & inter & tra & & & & & 1 & & & & & & $*$ & $*$ & $*$ & & * \\
\hline La casa Encendida (Madrid) & & & & & & & & & & - & & & & & & $*$ & $*$ & & 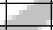 & * \\
\hline Museo Guggenheim (Bilbao) & & & & & 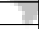 & & & & & & & & & & & & $*$ & * & r & \\
\hline Teatro Grec (Barcelona) & & & & & & & & & & & & & & & 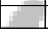 & & $*$ & & & * \\
\hline Centro Cultural de Egia (Bilbao) & & & & & & & & & & & 1 & & & $\mathrm{z}$ & +1 & & & $*$ & $*$ & \\
\hline Teatro Central de Sevilla & & & & & & & & & & & + & & & & & & & * & * & \\
\hline Teatro Fernán Gómez (Madrid) & & & & & & & & & & & 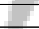 & & 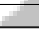 & & & & & & $*$ & * \\
\hline
\end{tabular}

incluso coreógrafos quedan fuera de los registros periódicos de la revista. La expansión de la danza se produce en múltiples direcciones en un proceso de imparable diversificación de categorías, modos, gestiones, propuestas, espacios y actividades derivados de la propia creación coreográfica.

$\mathrm{Al}$

observar comparativamente las tablas elaboradas en este estudio sobre compañías de danza contemporánea, festivales y espacios se detecta una ebullición en el surgimiento de compañías estables en la primera década y más inestables en la segunda década mientras sucede un desarrollo más notable tanto de espacios como de festivales y eventos en la segunda década

Universidad Carlos III; Centros de Cultura Contemporánea como el de Barcelona (2001) o la Casa de Cultura Ernest Lluch de Amara de Bilbao (2003), la Casa de Cultura de Egia en San Sebastián (2004) y en Bilbao (2007), La Casa Encendida en Madrid desde el 2005, Museos como el Guggenheim de Bilbao (2006), Sedes de Compañías como la de El Curro desde el 2004 y otros espacios como el Castillo de Castelldefels (2006), la Plaza de Lavapiés de Madrid (2009) o la Lonja de Pescado de Alicante (2009).

Los creadores de danza contemporánea están forjando sus trayectorias en gran medida fuera de España, lo cual se puede entender como un exilio obligado que aparece desde los inicios de la danza contemporánea en relación con la necesidad de formación específica con coreógrafos y compañías extranjeras. En este sentido, los procesos migratorios hacia el exterior (en busca de formación, de trabajo, de apoyo institucional o de público sensibilizado) o hacia el interior (el paso de compañías extranjeras por los teatros y eventos españoles y la invitación privada y más tarde pública a profesores y/o coreógrafos) son procesos fundamentales en la historia de la danza contemporánea debido a los años de letargoo aislamiento previo derivados de la dictadura. Este hecho aparece ilustrado en el análisis de la danza contemporánea en Valencia de Giménez (2001) y en su clasificación en etapas donde se describen entre otros las estancias de aprendizaje y las participación escénica internacional: limbo (1971-1979), gestación (1979-1982), apertura al exterior (1982-1984), eclosión (1984-1990) y frutos desde 1990. Sin embargo, la proyección internacional o mejor dicho las referencias extranjeras recogidas en la revista nos parecen escasas y aisladas, aparecen sólo algunas como Bélgica y Holanda (1995), Berlín (1999), Lisboa (2003), Nueva York (2004), Argelia (2005) París (2008), Florencia (2008), y México (2009), destacando este último por repetidas alusiones.

\section{Conclusiones}

A pesar de las limitaciones derivadas del carácter descriptivo de este estudio bibliométrico se ha de considerar un paso imprescindible para acercarse a la compleja realidad del desarrollo de la danza contemporánea en España. El análisis de estas dos décadas revela en primer lugar la importancia de los años previos a 1990, que escapan al registro de la revista objeto de estudio, por lo que sería preciso acudir a otras fuentes, en particular a la entrevista directa con las propias compañías y coreógrafos, así como con gestores y organizadores de eventos específicos.

La danza contemporánea ocupa diversos circuitos de visibilidad y/ o experiencia escénica, creemos que muchos de los espacios, eventos e analizada. Destaca en este sentido el protagonismo de las propias compañías y asociaciones de coreógrafos en busca de espacios de creación y representación; el reconocimiento y el apoyo institucionales suelen llegar, si llegan, después de un tiempo de heroica actividad autónoma. En la primera década se pueden distinguir varios momentos de incremento exponencial de compañías $(1990,1993,1997)$ mientras que en la segunda década el crecimiento es más uniforme con un solo pico en el año 2005.

En el análisis de espacios y eventos destacamos el paralelismo surgido entre ambos campos desde un punto de vista evolutivo en cuanto a la búsqueda de especificidad o distinción de la danza contemporánea respecto de otras formas de danza y al mismo tiempo el acercamiento a las artes no solamente escénicas sino plásticas: no obstante en cuanto a los eventos, la danza contemporánea conserva su ubicación en el marco de las artes escénicas mientras en los espacios parece adelantarse en el encuentro con las artes plásticas.

Desde una perspectiva geográfica, como límites de la fuente analizada, se perciben un comprensible sesgo local y un escaso seguimiento de la actividad ocurrida fuera de España en relación directa con las compañías o los coreógrafos. No obstante, con los datos disponibles sobre el transcurso del tiempo analizado, se apunta, al menos, una tendencia a incorporar actividades que suceden cada vez en puntos más lejanos a las órbitas directas de Madrid o Barcelona. En este sentido, la danza contemporánea parece contribuir a la lenta y necesaria descentralización de la danza en España en la medida en que la creación se nutre de nuevos mecanismos y procesos de interacción: entre entidades diversas, entre actores, creadores y público, y, finalmente, entre acción, creación y reflexión teórica.

\section{Referencias bibliográficas}

Arantzibia, I. (2010). Danza planificada. En Ddanza 22, 40.

Bravo, J. (1990). Bocanada Danza. En El Público 76, 116-117.

Esteler, S. (2010). Aliados con la creación. En Ddanza 23, 36-39.

Giménez, C. (2001). La danza contemporánea en la comunidad valenciana: los primeros pasos. Valencia: Centre Coreografic.

Heathfield, A. (2004). En mémoire des petites choses. En CND, La Ribot (pp. 13-21). Mertz\&Pantin: Centre Nacional de la Danse.

INAEM (2009). Plan General de la danza 2010-2014. Madrid: Ministerio de Cultura. http://danza.es/plan/PGD (Consulta marzo 2011).

Laguna, P. (2009). Entrevista a Ana Laguna. En Danzaratte 4 (6), 70-73.

Margarit, A. (2000). CIA Mudances 1985-2000. Barcelona: Autor.

Martínez, B. \& Menéndez, N. (1999). De 1975 a la actualidad. Últimas tendencias de la danza en España. En Amorós, A. \& Díez, José María, Historia de los espectáculos en España (pp. 360-372). Madrid: Editorial Castalia.

Van der Meer, M. (1990). Danat Dansa. En El Público 76, 76. 